\title{
EXPERIMENTAL STUDY ON THE TRIBOLOGICAL BEHAVIOR OF POLYMERIC MATERIALS USED IN SLIDING MOTION COUPLES
}

\author{
Ivona Camelia Petre ${ }^{1}$, Elena Valentina Stoian ${ }^{1}$, Cristiana Maria Enescu ${ }^{1}$, Veronica Despa ${ }^{1}$ \\ ${ }^{1}$ Valahia University of Targoviste, Faculty of Materials Engineering and Mechanics, 13 Sinaia Alley, 130004, \\ Targoviste, Romania \\ E-mails: petreivonacamellia@yahoo.com, elenastoian22@gmail.com, \\ cristianaenescu@yahoo.com, dumiver@yahoo.com
}

\begin{abstract}
The use of polymeric materials with thermoplastic properties, in the different types of rubbing couplings, is of scientific and technical interest. Due to the mechanical and technical properties superior to the metallic materials, a thorough analysis of the behavioral mode in operation is necessary, which justifies the development of research in this field. The objective of this paper is to carry out an experimental study on the tribological behavior of the Relamid polymeric material, on a tribological test stand in contact with a harder surface (OL42). The material under analysis is a thermoplastic, high performance material used to make the organs of moving machines. It is used in the construction of many couplings with sliding motion due to the good wear behavior under the action parameters. The experimental data obtained show that the wear of any car body is affected by the operating conditions (pressure, speed) and the material of the coupling. As a result of the experimental results obtained, it is appreciated that optimal constructive solutions can be found from the point of view of the phenomena related to friction, wear and tear for choosing such material.
\end{abstract}

Keywords: Polymeric Material, Sliding Motion, Friction Coefficient, Operating Conditions, Wear.

\section{Introduction}

The polymeric materials used to make the sliding motion couples play an essential role in the future technological development of all the highly industrialized countries. The process in understanding the tribological behavior of polymeric materials involves multiple experimental researches, until its introduction and use in the makingof different machine organs.

Due to the good properties related to wearing resistance, vibration absorption capacity, thermoplastic polymeric materials succesfully replace metallic materials. Due to the fact that their properties vary during operation, structural changes, changes in mollecular mass, orientation of mollecular chains by mechanical-thermal processes, modification of the cristallinity degree for crystalline ones can occur [1].

These changes lead to the need to test polymeric materials in conditions as close as possible to those of industrial application. Knowing how tribological behavior of polymeric materials under experimental condition leads to a much easier selection in industrial application.

Relamide is an assortment of polymeric composition based on polyamide 6 , graphite additive and thermostabilized. It has superior mechanical properties, self lubrication properties, low coefficients of friction, ans is resistant in corrosive enviroments. The presence of the thermostat makes it possible to be used at high temperatures. The material under analysis is a high performance thermoplastic material used for making moving machine parts, bearings, bushings, sliding surfaces etc. Subjected to usage and high volume. Polyamides are polymers with long bonds containing amide units. $(\mathrm{N}-\mathrm{H}-\mathrm{C}=\mathrm{O})$. These polymers are obtained by polymerizing an acid with amides. The reaction to obtain Polyamide 6 is the following [1]:
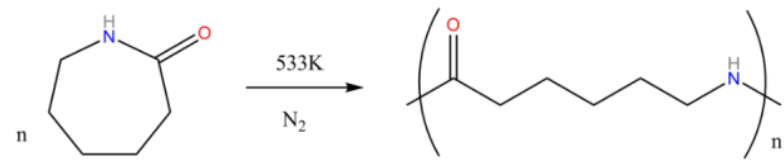

Polyamide 6, nylon 6 (PA6) or polycaprolactamis part of the technopolymer category, due to the excellent balance between performance and cost. Its characteristics related to friction and low wear, long service life under the action of the operating parameters, the vibration absorption in operation recommends it for use for this type of rubbing couplings. The work carried out on a tribological stand for measuring the friction proposes an experimental analysis regarding the evolution of the friction coefficient of the Relamid material in contact with a metallic material (OL42) and its wear by modifying different working parameters. 
The work will also analyse the way of the abrasion behavior under the action of a conical penetrator.

\section{Theoretical Considerations Related to the Friction and Wear Behavior of Polymeric Materials}

Please note that the first paragraph of a section or subsection is not indented. The first paragraphs that follows a table, figure, equation etc. does not have an indent, either.

Subsequent paragraphs, however, are indented. From the research carried out it was found that although the polymeric materials have lower rigidity and resilience than the metallic materials, they are successfully used in industrial application where the friction couples have a slip motion.

The rubbing of polymeric materials in the specialized literature is explained according to adhesion friction theories [2-11]. There are significant differences of these materials in use compared to the behavior of friction and wear of metallic materials.

We encounter a few differences between those materials:

- One refers to the evolution mode of the friction coefficient which for composite materials tends to decrease with increasing load;

- Another difference relates to the decrease of the friction coefficient with the decrease of the geometric contact surface such as non-conforming (hertzian) frictional couples;

- Another aspect is related to the friction that can increase with the increase of the temperature of the materials of the joint during the period of operation;

- An undesirable phenomenon is related to the fact that although in a resting state, under contact the contact surface of the coupling may increase due to creep.

In the case of polymeric materials it has been found that at low sliding speeds, the coefficient of friction can increase greatly due to therma softening. In contrast, at high speeds it has been found that the friction may decrease due to the appearance of a film of melted lubricating material $[7,8,12,13]$.

For the analysis of wear, it will be taken into account that this is only a reduction of the dimensions of the materials of the rubbing joint during the operation. Its size depends on many parameters and occurs in those parts of the contact surface that are parts of the actual friction area.

You can determine the linear wear intensity, if you talk about the thickness of the worn layer perpendicular to the friction surface, knowing the friction length for each element of the coupling separately, depending on the kinematics and the shape of the elements in contact.
If where to weight loss then we are talking about estimating the gravimetric intensity of wear. Displayed equations are centered and set on a separate line.

$$
I_{g}=\frac{\Delta m}{L_{f}}
$$

where: $\Delta m$ is the loss of material $[g]$;

$L_{f}$ is the length of friction the pin goes through $[\mathrm{km}]$.

$$
L_{f}=L_{o f} \cdot N_{c}
$$

where: $N_{c}$ is the number of cycles (courses, rotations);

$L_{o f}$ is the length of friction for one pin rotation.

In the vast field of mechanincal stresses, during the operation of any frictional coupling, the harder asperities of the metallic material can scratch the surface of the softer material (the polymeric material) $[6,7,8]$. This form of wear (abrasion wear) has aggressive forms of manifestation due to the difference between the hardnesses of the contact materials, in which the polymeric material can undergo irreparable changes when sliding on a surface with higher hardness (steel).

The mechanical response to the scratching that such a material can have is a means of obtaining information on the mode of sliding deformation, without giving other information such as those related to the properties of the material. The depth of the scratching for such a situation depends largely on the normal driving force and the size of the chopping angle $[6,11,12,13,14]$. In these conditions, the depth of penetration of the cone on the distance of travel to a single passage will be:

$$
d=\left(\frac{F_{n}}{H \cdot 0,5 \cdot \pi}\right)^{1 / 2} \cdot \frac{1}{\operatorname{tg} \alpha}
$$

where: $F_{n}$ is the normal pressing force $[N]$;

$\mathrm{H}$ - the flow resistance of the surface material which can be considered as the hardness $\left[\mathrm{N} / \mathrm{mm}^{2}\right]$;

$\alpha$ - the inclination angle of the cone with the direction of travel $\left[{ }^{o}\right]$.

Taking into account the data from the specialized literature in the paper, we analyze the evolution of the friction coefficient under the action of the different parameters (speed, pressure), the evolution of the wear of the Relamid/OL42 material for the experiment conditions and the penetration depth under the action of a conical penetrator on the stand, tribological tests performed in this regard. 


\section{Description of the Tribological Stand}

The device shown in figure 1 is driven by an electric motor (8) which transmits the movement to the main shaft (5) by means of a coupling (6). At the end of the main shaft (5), widened with radial axial bearings (body 4) is a disc (2) on which the movabale specimen (3) of the metallic material (OL42) is fixed. The fixed specimen (1) made of polymeric material, cylindrical in shape, is mounted in the fixing device (7), with the possibility of moving horizontally (within the radius of the movable plate 3). The fastening device is reinforced by means of the fastening columns (10). The speed of the shaft can be varied by means of a frequency converter. The loading of the fixed specimen (1) is carried out by applying weights (13) to the body of the fastening device (7).

For the measurement of the friction coefficient, the method is mainly used with resistive tensometric transducer. This method is based on the fact that the frictional force produces the displacement of one of the parts of the fricitonal joint, which can be taken over by a resistive tensometric transducer.

The entire device is connected to a data acquisition board (12).

\section{The Experimental Part}

The materials used in the experimental part were: an OL42 steel plate placed on the rotating disk (position 2 in figure 1) and a polymeric material - Relamid palced in the fastener (7).

The analysis of the samples on the test stans was done under the conditions of dry friciton, because the polymeric material is a slightly hygroscopic material. This is due to the fact that at the interface polymeric material-metal material weak bonds appear that modify their structure $[1,6,11,12]$.

The experimental part had the following research directions:

a. Establishing the influence of the operating parameters (pressure, spped) on the friction coefficient;

b. Establishing the wear of the polymeric material under the action of the operating parameters (pressure, speed);

c. Establishing the penetration depth under the action of a conical pentrator.

For the experiment, cylindrical specimens were used, which were weighed and measured before the start of the experiment. The steel plate was washed and degreased with impurities before each experiment.

- To analyze the evolution of the friction coefficient with operating parameters, the specimen fastener was loaded with weights, the normal pressing force being $F_{n 1}=0,5 N, \quad F_{n 2}=1 N$, $F_{n 3}=5 \mathrm{~N}$.

For the evaluation of the friction coefficient an average of 3 measurements of the friction coefficient was made during each test and not as a friction value at an given time.

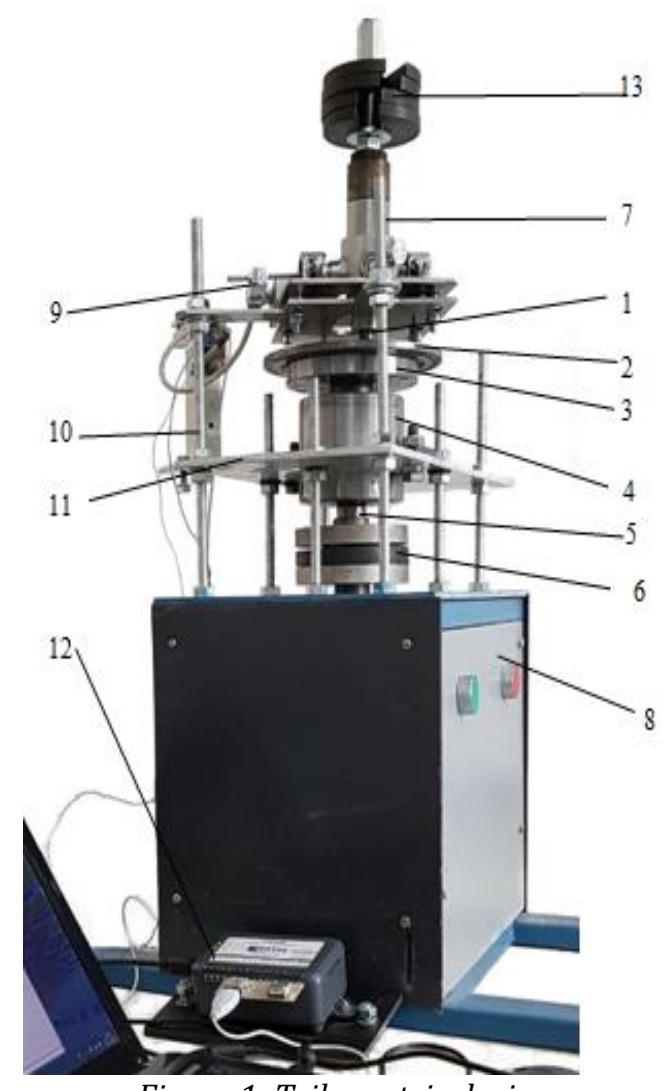

Figure 1: Tribometric device

Sliding speeds were varied between $v=0,2 \ldots 0,8 \mathrm{~m} / \mathrm{s}$. The operating period was 15 minutes. The results of the measurements are presented in graphical form in figure 2 .

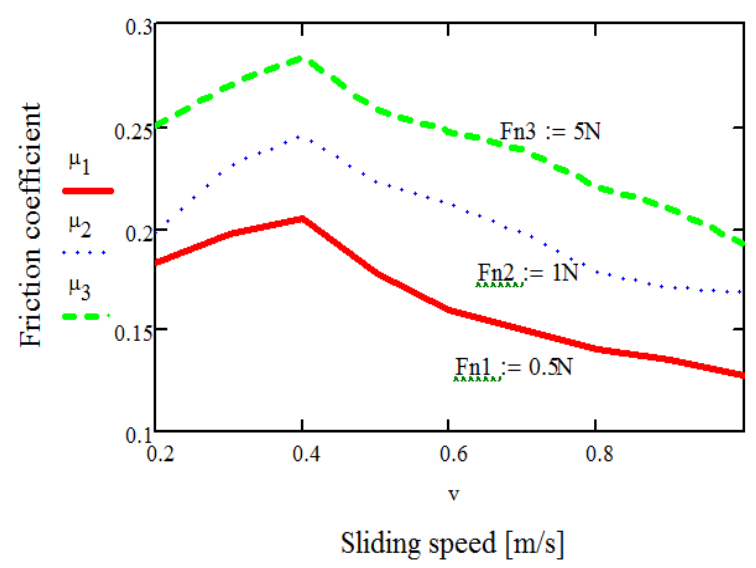

Figure 2: Evolution of the coefficient of friction for different loads of speed 
It is worth nothing a decrease in the value of the coefficient of friction as the speed increases. This according to the adhesion theory is expalined by the formation of a molten film from the thermoplastic material - practically the contact would be reduced to the friction between two materials of the same nature (polymer/polymer).

- For the tribological analysis of the wear behavior of the Relamid material, the weight loss of the samples under analysis was determined by measuring, after the materials were tested for 30 minutes, at a speed of $v_{1}=0,2 \mathrm{~m} / \mathrm{s}$, respectively $v_{2}=0,1 \mathrm{~m} / \mathrm{s}$ and loaded with forces $F_{n 1}=0,5 \mathrm{~N}$, $F_{n 2}=1 N, F_{n 3}=5 N$.

Table 1 presents the average values of the analyzed tribological characteristics, for three tests performed.

Table 1. Tribological characteristics.

\begin{tabular}{|c|c|c|c|}
\hline $\begin{array}{c}\text { Loading } \\
F_{n}[N]\end{array}$ & $\begin{array}{c}\text { Speed } \\
v[\mathrm{~m} / \mathrm{s}]\end{array}$ & $\begin{array}{c}\text { Average friction } \\
\text { coefficient } \\
\mu_{m e d}\end{array}$ & $\begin{array}{c}\text { Weight loss } \\
\Delta m[\mathrm{~g} / \mathrm{h}]\end{array}$ \\
\hline \multirow{3}{*}{0,5} & 0,2 & 0,183 & 0,028 \\
\cline { 2 - 4 } & 0,1 & 0,131 & 0,023 \\
\hline \multirow{2}{*}{1} & 0,2 & 0,197 & 0,052 \\
\cline { 2 - 4 } & 0,1 & 0,172 & 0,048 \\
\hline \multirow{2}{*}{5} & 0,2 & 0,250 & 0,068 \\
\cline { 2 - 4 } & 0,1 & 0,210 & 0,056 \\
\hline
\end{tabular}

From the experimental data obtained it is obvious that the wear of the couple of analyzed materials increases with the increase of the operating conditions.

- For the tribological analysis of the behavior under the action of a conical penetrator, the movale specimen will be from relamid and the fixed specimen will be a cone from OL42 which will have the angle at the tip of $\alpha_{1}=160^{\circ}, \alpha_{2}=120^{\circ}$, $\alpha_{3}=20^{\circ}$. The defects of the tapered pins were $12 \mu \mathrm{m} /$ radius $[7,8,16]$. The samples were loaded in turn with the respective forces $F_{n}=0,5 \mathrm{~N}, F_{n}=1 \mathrm{~N}$.
For each experiment, 3 similar tests were performed for which the penetration depth was measured.

Figure 3 shows the theoretical evolution (corresponding to the relation 2) and the experimental one, of the penetration of the polyleric material after 30 minutes of device operation.

The difference between the theoretical and experimental penetration depth values is only noted for the small penetrator semicircles. This is explained by the fact that the friction is absent at the moment of penetration due to the elasticity properties of the material. For higher values of the penetrator semiconductor it is noted that the differences are small.

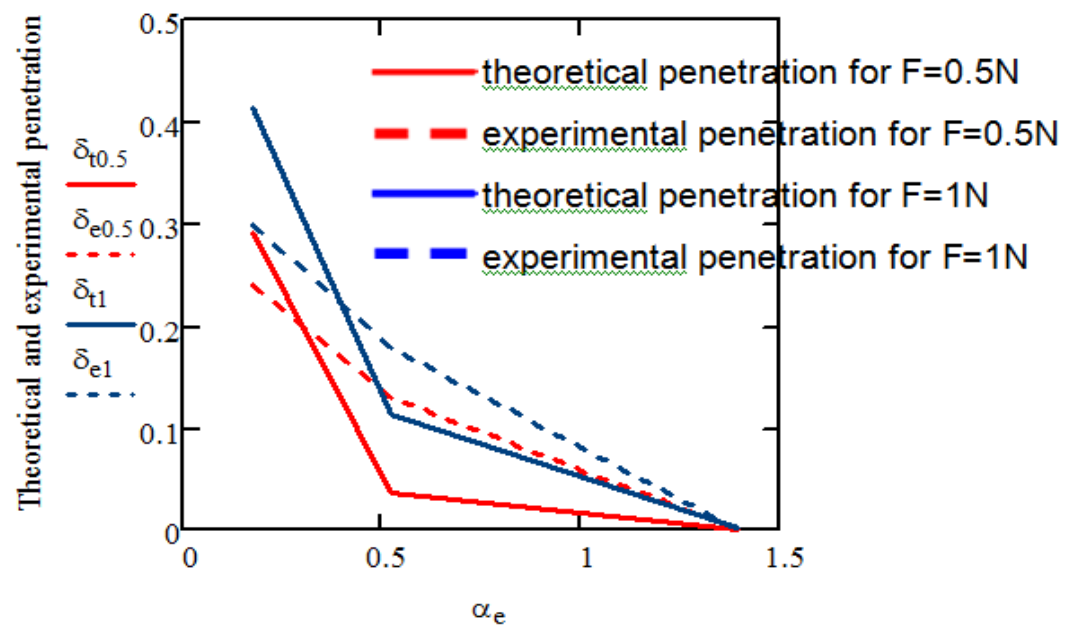

Angle of inclination

Figure 3: The evolution of the penetration with the inclination angle of the cone and the loading 


\section{Results and Discussions}

The recordings made by the translator indicate a variability of the friction force for the same value of the normal pressing force. This variation is due to the quality of the surafec of the disk, the processing mode (by the size of the asperities) contributing to the application of the normal force in dynamic regime. According to the behavior of the Relamid material during friction and wear, the following aspects can be highlighted:

- In operation, the coefficient of friction decreases with the increase of the sliding speed. This is due to the fact that in many plastics that slide on harder surfaces (metallic materials) a plastic transfer film may appear on the mating surface. This film $[3,4,5,6]$ practically defines the way of friction and wear of the coupling because once the transfer film is formed a plastic - plastic interaction occurs. The transfer film becomes much thinner at higher speeds and contains strongly oriented molecular chains parallel to the slip direction. Initially the coefficient of friction has a higher value, because the transfer film did not form, and then decreases.

The size of the wear of the rubbing joint materials depends on its operating mode. The higher the operating factors (pressure, speed etc.), the higher the wear and tear.

- It is found both theoretically and experimentally that the penetration depth increases with increasing load and decreases with increasing penetration semiconductor. This is due to the size of the contact surface and the pressure exerted by the conical penetrator

- At low values of the penetrator semiconductor it is appreciated that the deformations of the soft material (Relamid) are higher, which also leads to value of the higher friction coefficients. The explanations given are related to the viscoelastic properties of the polymer $[12,13]$.

\section{Conclusion}

The purpose of the paper was to confirm/ invalidate the researches carried out in the specialized literature on the behavior of polymeric materials. It did not seek to highlight the qualities or defaults of the material analyzed.

The aspects presented in this paper can be considered as a starting point in choosing the material of a rubbing joint, the lubrication mode and why not the exploitation mode of the coupling.

\section{References}

[1] Cosmeleaţă G., Enescu, C. Zaharia, M.: Materiale compozite cu matrice polimerică, vol. I, Ed. Printech, București (2006).
[2] Rîpa M., Deleanu L.- Deteriorări în tribosistemele mecanice, Editura Zigotto, Galaţi (2008).

[3] Tabor, D.: Friction, Lubrication aned wear, Source: Mechanical design hanbook (2003).

[4] Bhushan, B.: Introduction to tribology, Second edition, A John Wiley\& Sons, Ltd., Publication (2013).

[5] Briscoe, B. J., and D. Tabor: Shear Properties of Polymeric Films, J. Adhesion, vol. 9, (1978).

[6] Lancaster, J. K.: Friction and Wear, in "Polymer Science, a Materials Science Handbook," A. D. Jenkins ed., North Holland Publishing Co., Amsterdam, The Netherlands, (1972).

[7] Petre I, Popescu I.N., Ungureanu D. N. - Aspects regarding the tribological behavior of Turcite and Relamid polymeric materials, in sliding motion couples, Revista materiale plastice, vol.56, No. 1 (2019).

[8] Petre I., Enescu M. C., Stoian E. V. - Research Regarding the Evolution of Friction Coefficient in a Friction Torque Like a Plastic Material / Steel for Different Parameters, Revista materiale plastice, vol 56 no. 4, (2019).

[9] Rubenstein C.: Lubrication of Polymers, Journal of AppliedPhysics 32, 1445, (1961).

[10] Rusănescu C.O., Rusănescu M., Anghelina F. V., Popescu I.N. - Study Deformability Ecological Steel (41Cr4), Revista Materiale Plastice 55, No. 3, (2018).

[11] Maftei L., Deleanu L., Andrei G., Influence of Sliding Speed and Average Pressure in Dry RegimUpon Wear of Composite with PA and Micro Glass Spheres, The Annals Of University Dunărea de Jos of Galati, VIII, (XV), Issue 1, Tribology, (2009).

[12] Rus D., Căpitanu L., Bădiță L.L. - A qualitative correlationbetween friction coefficient and steel surface wear in linear dry sliding contact to polymerswith SGF, Friction, 2, 1, (2014).

[13] Petre I. - Determining the functional and material properties needed for abrasive wear prediction,7th International Conference on Advanced Concepts in Mechanical Engineering, IOP Conf. Series: Materials Science and Engineering 147 (2016)

[14] Petre, I., Bratu V., Enescu M. C., Stoian E. V., Anghelina F. V. - Study on Degradation Mechanisms of the Inner Surface of Fire-Arms, Key Engineering Materials, Vol. 750, ISSN: 1662-9795, pp 69-74, (2017).

[15] Petre, I.C., Catangiu, A., Popescu, I.N., Ungureanu, D. N., Negrea, A., Poinescu, A.A., Enescu, M.C., Stoian, E.V., Despa, V. Tribometric device for determining friction forces and friction coefficients in the case of dry friction materials, The Scientific Bulletin of Valahia University, Materials and Mechanics , 16 , no. $15,17,(2018)$.

[16] Rusenescu C.O., Risenescu, M., Biris, S S., Voicu Gh., Enescu C.M.: Research on the Mechanical Characteristics of a Microalloyed Steel with $\mathrm{V}$ in the Agreement with Environmental Trends, REV.CHIM.(Bucharest), 70, No. 5, (2019). 